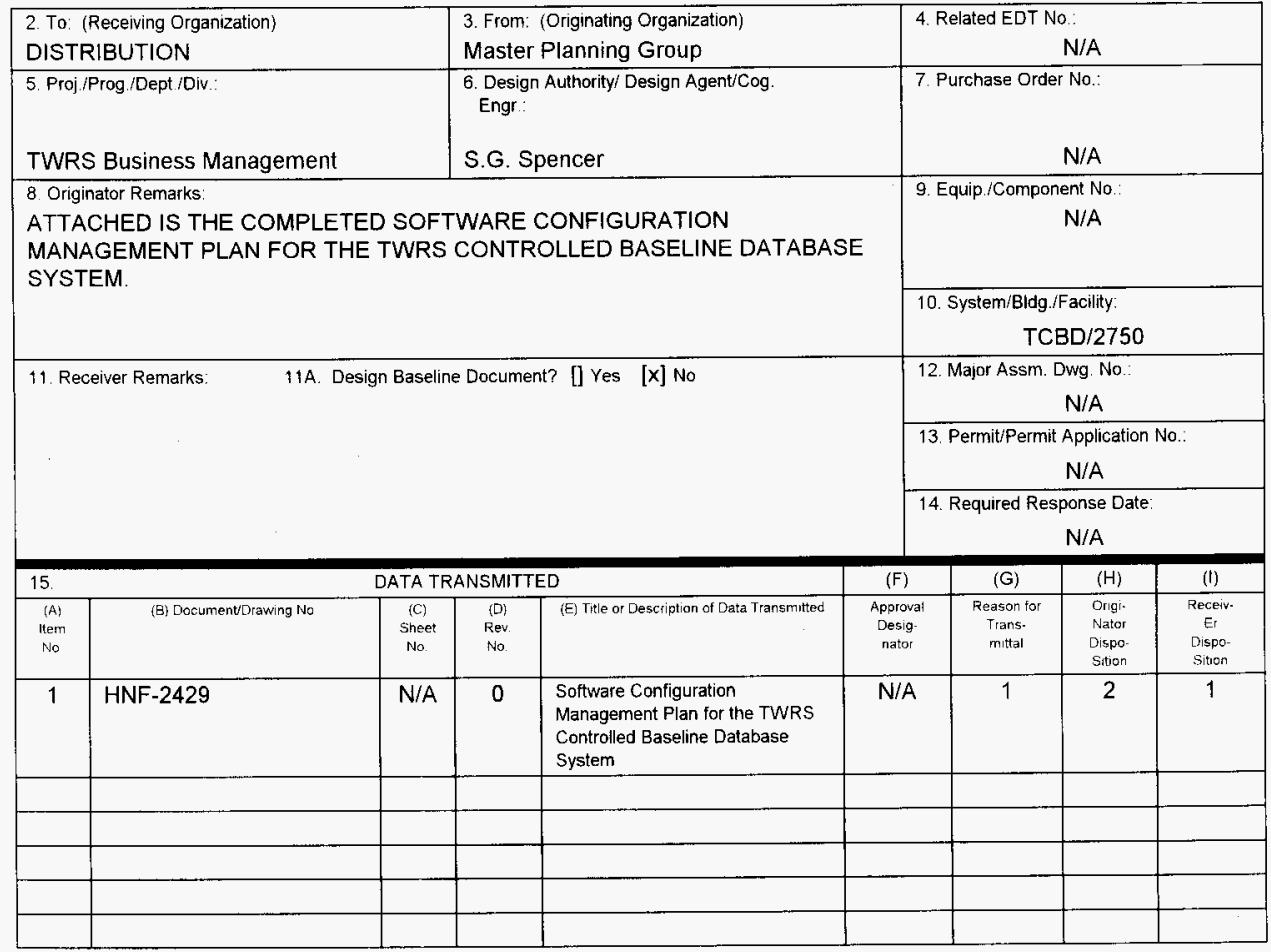

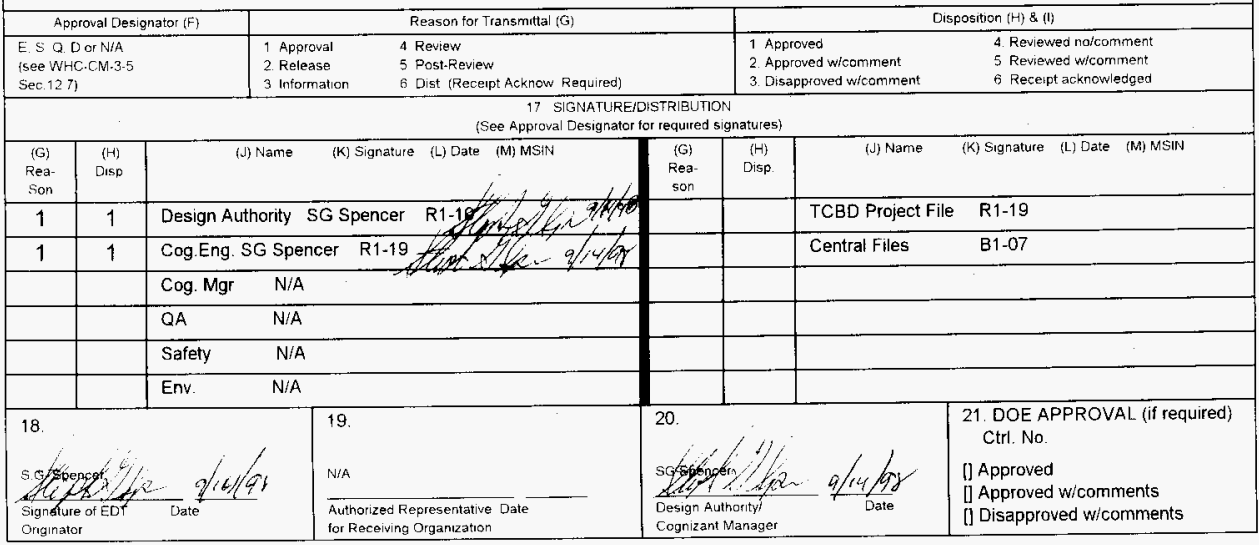


HNF-2429, Rev. 0

\section{Software Configuration Management Plan for the TWRS Controlled Baseline Database System}

S. G. Spencer

Lockheed Martin Hanford Corp., Richland, WA 99352

U.S. Department of Energy Contract DE-AC06-96RL13200

$\begin{array}{ll}\text { EDTIECN: EDT } 625658 & \text { UC: } 2030 \\ \text { Org Code: } 72240 & \text { Charge Code: D1K51 } \\ \text { B\&R Code: EW3120075 } & \text { Total Pages: } 2223 \underset{q-23}{\sim}-98\end{array}$

Key Words: TWRS Controlled Baseline Database, System, Configuration Management, Database, Software Change Request \& Problem Report.

Abstract: TWRS Controlled Baseline Database, formally known as the Performance Measurement Control System, is used to track and monitor TWRS project management baseline information. This document contains the configuration management approach for software changes within the database system

TRADEMARK DISCLAIMER, Reference herein to any specific commercial product, process, or service by trade name, trademark, manufacturer, or otherwise, does not necessarily constitute ox imply its endorsement, recommendation, or favoring by the United states Government or any agency thereof or its contractors or subcontractors.

printed in the United States of America. To obtain copies of this document, contact: Document Control Services, P.O. Box 950, Mailstop H6-08, Richland WA 99352, Phone (509) $372-2420 ; \operatorname{Fax}(509) 376-4989$.
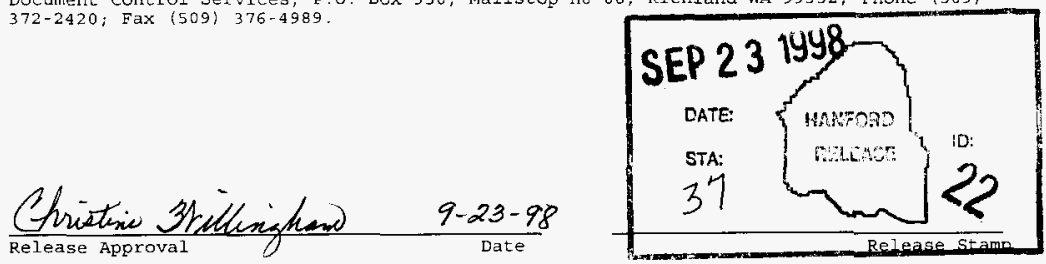

\section{Approved for Public Release}


PRIMAVERA is a registered trademark of Primavera Systems, Inc.

MICROSOFT is a registered trademark of the Microsoft Corporation 


\title{
SOFTWARE CONFIGURATION MANAGEMENT PLAN FOR THE
}

\author{
TWRS CONTROLLED BASELINE DATABASE SYSTEM
}




\section{TABLE OF CONTENTS}

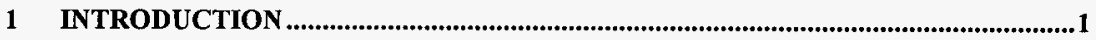

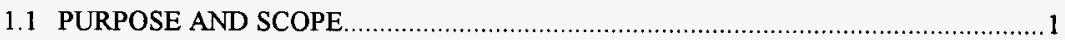

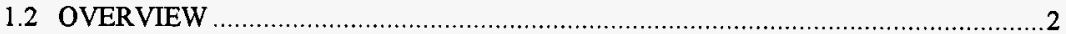

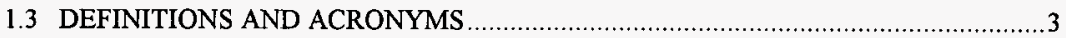

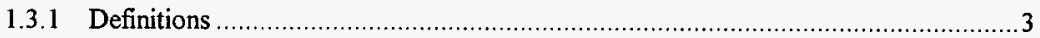

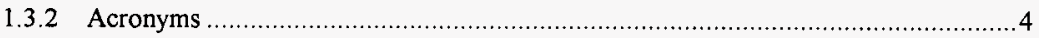

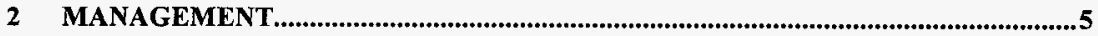

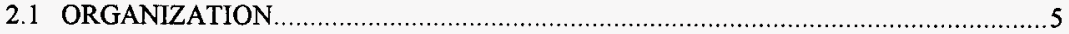

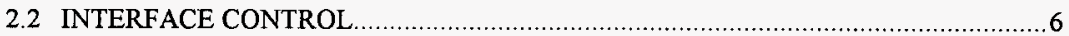

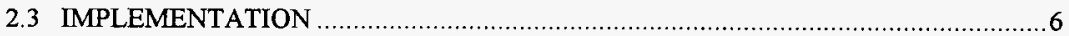

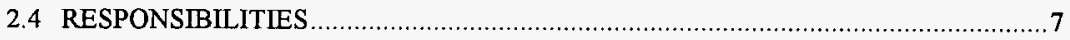

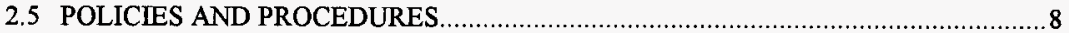

3 SOFTWARE CONFIGURATION MANAGEMENT ACTIVITIES...............................8

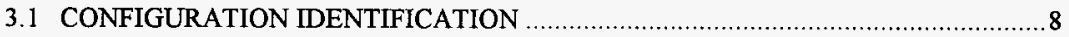

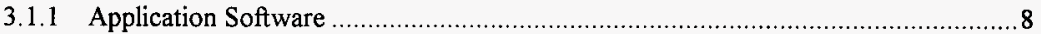

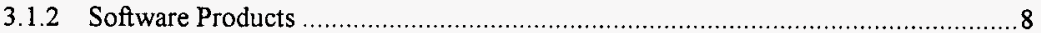

3.1.3 Automatic Data Processing Hardware ..............................................................

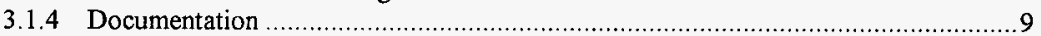

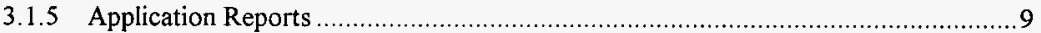

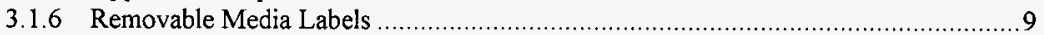

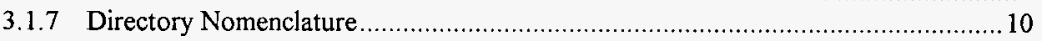

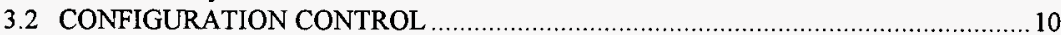

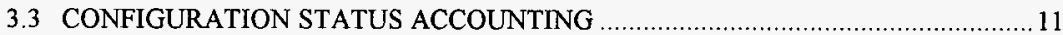

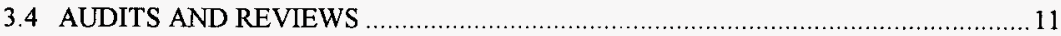

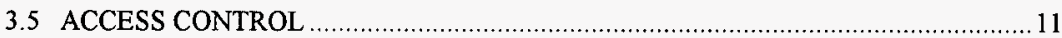

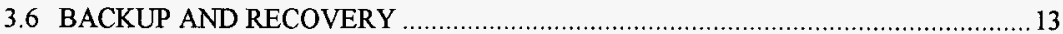

4 TOOLS, TECHNIQUES AND METHODOLOGIES .......................................................

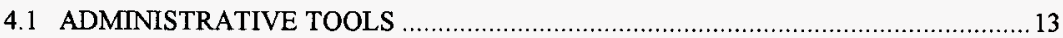

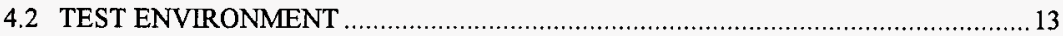

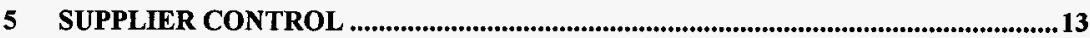

6 RECORDS COLLECTION AND RETENTION_......................................................14

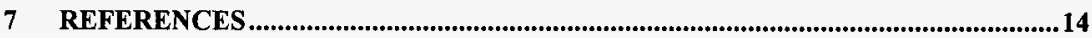

APPENDIX A: TCBD SOFTWARE CHANGE REQUEST AND PROBLEM REPORT

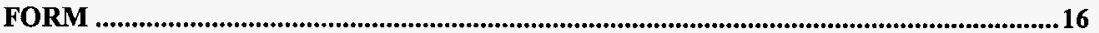




\section{APPENDIX C: TCBD SCMP, V\&V PLAN, AND MTP RELATIONSHIP CHART...........18}

\section{FIGURE}

1 Change Request and Problem Report Process Flow Chart.............................12

\section{TABLE}

1. Responsibilities Matrix. 


\section{INTRODUCTION}

This Software Configuration Management Plan (SCMP) provides an effective means to control changes to the Tank Waste Remediation System (TWRS) Controlled Baseline Database (TCBD).

The TCBD was developed as the electronic data repository for cost, schedule, and technical administrative baseline information for the TWRS Program. The TCBD system was originally known as the Performance Measurement Control System (PMCS). Therefore, for simplicity, all references to TCBD are equivalent to PMCS references. The TCBD requires activity-based cost estimates and selected financial information to be imported from the master databases containing this information.

\subsection{PURPOSE AND SCOPE}

This SCMP provides the instructions for change control of the baseline TCBD system. Identified are requirements and responsibilities of the database development and maintenance personnel, the change control process, and necessary documentation.

The TCBD system currently consists of functional areas that are either in production or development. Production functional areas include the following:

- PMCS Security Module

- PMCS Main Menu

- Work Breakdown Structure (WBS) Module

- Integration Module (including work scope definitions and estimates)

- Milestone Module

- Engineering Change Notice (ECN) Module

- Primavera(P3)/PMCS Module.

Development functional areas include the following:

- Technical Basis Review/Cost Estimating Input Sheets

- Milestone Tracking and Reporting.

The associated TCBD design basis documentation is provided in the High-Level Software Requirements Specification for the TWRS Controlled Baseline Database System (LMHC 1998a). Changes to design basis documentation, via ECN, will require following this SCMP to evaluate TCBD system impact.

This SCMP applies to the TCBD system production functional areas (i.e., becomes "production" after formal acceptance and operational testing of a functional area) and applies whenever a system test exception, problem, or change request is identified. TCBD system development and maintenance personnel use this SCMP. 
This SCMP can also be used for long-term system maintenance. Two other TCBD documents exist to be used in conjunction with this SCMP for maintenance purposes: the System Maintenance Test Plan for the TWRS Controlled Baseline Database System (LMHC 1998b); and the System Maintenance Verification and Validation Plan for the TWRS Controlled Baseline Database System (LMHC 1998c). The TCBD System Maintenance Approach is shown via a relationship chart and is shown in Appendix C. Reference to these documents also appear in SCMP processes described in Section 2.

This SCMP does not apply to the development functional areas until they are released for integration with the main TCBD production system through formal acceptance testing. Also, this SCMP does not apply directly to external systems that interface with the TCBD system, but can be used to report issues that arise with these system interfaces.

This SCMP does not apply to reports and data generated by the TCBD system except when specifically identified. Control of information produced by the software, after it has been exported, is the responsibility of the receiving organization. However, TCBD data sources are the "official" data.

\subsection{OVERVIEW}

The TCBD project, formally known as the Performance Measurement Control System, was initiated to facilitate specific data integration processes surrounding the project scheduling system environment. The Performance Measurement Control System Project Management Plan (LMHC 1997) provides a brief project history and acquisition planning information.

Specifically, the TCBD project was initiated to facilitate specific data integration processes of the Westinghouse Hanford Company that operated the Financial Data System (FDS) and ICF Kaiser Hanford (Kaiser) that operated Kaiser Engineering Management System and Kaiser Financial System, including the project scheduling system environment.

Since contractor changeover, the Westinghouse Hanford Company portion has been assumed by Lockheed Martin Hanford Company (LMHC) and the TWRS and Kaiser information has been assumed by Fluor Daniel Hanford (FDH). At the time of this writing, the FDS has been retired and replaced by a Performance Module that receives data from Primavera P3.

The TCBD system data integration processes have been migrated into a client-server environment and contain several production and development modules to manage TWRS information for data input and retrieval (see Section 1.2).

The TCBD system architecture consists of seven file servers, with either Microsoft Windows ${ }^{1}$ NT 3.51 or NT 4.0 as the Operating System $(\mathrm{O} / \mathrm{S})$. The Relational Database Management System is Microsoft SQL versions 6.0 or 6.5. Three of the servers are domain

\footnotetext{
${ }^{1}$ Microsoft Windows is a tradename of the Microsoft Corporation.
} 
controllers for the TCBD domain on the Hanford Local Area Network. One of the domain controllers is designated as the primary domain controller. The other two domain controllers are designated as Backup Primary Domain Controllers (BPDC).

One BPDC stores the TCBD production client software, source-code, File Transfer Protocol (FTP) services, and all the TWRS/Spent Nuclear Fuel P3 schedules. The other BPDC is used as a fail-over standby and maintains a copy of the production library FTP services and is located in the 300 Area. The other four servers are SQL servers (production server, production server backup located in the 300 Area, reporting server [Internet ready], and test server).

The TCBD system will process large amounts of data between the mainframe and the servers and provide for the retrieval of that data from the local servers at the workstations.

Windows NT has the ability to simultaneously process data and allows the servers to maintain productivity at a rate consistent with data retrieval demands. Servers will have multiple concurrent users, who will update the database throughout the workday. The client-server environment will provide the ability to have multiple users concurrently update the server database tables, including moving work plan data to and from three interface systems during day and evening hours.

At the time of this writing, the TCBD system has interface capabilities for the FDS and Primavera (P3), and does not interface with any other data system. However, since the FDS has been retired, it is planned that the TCBD will potentially interface with its replacement, the Performance Module. It is also planned for the TCBD to interface with the Central Milestone Module, the Hanford Site official milestone database. Currently, the only data highway is between the TCBD/FDS and TCBD/Primavera (P3).

FDS data that is downloaded must pass the validation test before being loaded into the system SQL tables. Any modifications to TCBD file formats should be communicated per this SCMP via the Software Change Request and Problem Report (SCR/PR) form, in Appendix A.

\subsection{DEFINITIONS AND ACRONYMS}

\subsubsection{Definitions}

Client/Server: Description of a distributed computing environment where the computing load is distributed to varying degrees between the workstation and the Relational Database Management System.

\section{Maintenance Test Plan:}

A plan that provides guidance to provide an effective process to test the maintenance and enhancements made to a system prior to release of revisions into the production environment. 
Production: A module that has been released for system use following acceptance by the customer.

Software Change Request and Problem Report (SCR/PR):

A form that identifies a proposed change to, or a suspected problem with the TCBD system. A SCR/PR may identify a new function, modify an existing function, or report suspected problems of the software or system hardware, at varying levels of priority.

Software Configuration Management (SCM):

A set of management disciplines within the context of the software engineering process that applies technical and administrative direction and surveillance. It identifies and documents the functional and physical characteristics of a product, controls changes to those characteristics, and it records and reports the change processing and implementation.

Validation: Process of analyzing information to determine whether it conforms to certain predefined parameters of completeness and consistency.

Verification and Validation Plan (VVP):

A plan that defines a process to perform verification and validation activities for a system during the software development life cycle.

Verification: To ascertain that either an activity has been performed or a result is correct.

\subsubsection{Acronyms}

$\begin{array}{ll}\text { ADP } & \text { Automatic Data Processing } \\ \text { BPDC } & \text { Backup Primary Domain Controller } \\ \text { BMO } & \text { Business Management Organization } \\ \text { CCB } & \text { Change Control Board } \\ \text { FDS } & \text { Financial Data System } \\ \text { FTP } & \text { File Transfer Protocol (used for moving files from the mainframe to a server). } \\ \text { LMHC } & \text { Lockheed Martin Hanford Company } \\ \text { LMSI } & \text { Lockheed Martin Services, Inc. } \\ \text { Kaiser } & \text { ICF Kaiser Hanford } \\ \text { MTP } & \text { Maintenance Test Plan } \\ \text { O/S } & \text { Operating System } \\ \text { P3 } & \text { P3 Primavera } \\ \text { PMCS } & \text { Performance Measurement Control System } \\ \text { SCMP } & \text { Software Configuration Management Plan } \\ \text { SCR/PR } & \text { Software Change Request and Problem Report } \\ \text { SQL } & \text { Structured Query Language } \\ \text { TWRS } & \text { Tank Waste Remediation System } \\ \text { TCBD } & \text { TWRS Controlled Baseline Database }\end{array}$




$\begin{array}{ll}\text { V\&V } & \text { Verification and Validation } \\ \text { VVP } & \text { Verification and Validation Plan } \\ \text { WBS } & \text { Work Breakdown Structure }\end{array}$

\section{MANAGEMENT}

\subsection{ORGANIZATION}

LHMC, TWRS Business Management Organization (BMO) is designated as system owner, operator, and maintenance authority. The TWRS BMO identified the need for the TCBD. The TWRS BMO users have established all requirements for the database and are responsible for maintaining database integrity and control (after the interface data has been received). Initial interface data control and integrity is maintained through functional and administrative processes and is the responsibility of the database owners who are providing the data.

The specific groups within the TWRS BMO affected by this plan are the Financial Management and TWRS Management Support Project, Master Planning, and the Financial Control Integration \& Reporting. The interfaces between these organizations are through normal line management chain of command.

The Master Planning Group is assigned the responsibility to continue development and maintenance of the TCBD. This group maintains information that includes identification of requirements and changes to those requirements in a TCBD project file. They are responsible for the issuance, maintenance, and change authority of this SCMP.

LHMC, TWRS TCBD Users are designated as providing the project's requirement changes for implementation and also testing of the TCBD during development. The Master Planning Group coordinates and monitors the user's requests for system requirements (new/existing) as well as beta and acceptance testing. Users are those individuals and organizations needing data or information from the TCBD and having both a need-to-know and the proper training and authority to access the database. Each user or user organization is required to comply with the established requirements and procedures governing the TCBD.

Lockheed Martin Services, Inc. (LMSI) is designated the TCBD developer, maintainer, and custodian until acceptance and process testing of the system has been completed via the TWRS BMO. Once this occurs, the TCBD will be completed and the software transferred to the system owner.

The primary programming for the TCBD was developed by Selfware, Inc. The Automatic Data Processing (ADP) Acquisition Plan, Systems Development \& Support Services for TWRS Performance Measurement and Control System, Acquisition Plan No. WHC94-705286 identifies workscope, deliverables, and cost. Selfware, Inc. configuration management practices are not included in this SCMP 


\subsection{INTERFACE CONTROL}

This SCMP is the only control mechanism to be used for the TCBD system, except in cases where the ECN process is designated for system documentation.

The Change Control Authority is via a CCB that is appointed by the LMHC-BMO CCB Chair designated in Table 1. The CCB roles and responsibilities are per this SCMP.

\subsection{IMPLEMENTATION}

This SCMP becomes effective, for the TCBD system production functional areas, whenever a system problem or change request is identified or when a development module is to be integrated into the baseline system as a production module.

Version change control of source code and executables become effective in these cases: 1) major revisions when released for integration testing and/or major issues, and 2) minor revisions when released for production changes. 


\subsection{RESPONSIBILITIES}

Table 1. Responsibilities Matrix.

\begin{tabular}{|c|c|c|}
\hline Wornoworion & 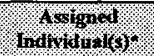 & 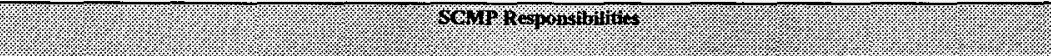 \\
\hline Software Owner & $\begin{array}{l}\text { S.G. Spencer } \\
\text { (LMHC-BMO) }\end{array}$ & $\begin{array}{l}\text { - Assigns Design Authority (Cognizant Engineer), who is Change Control Board (CCB) member. } \\
\text { - Assigns the Software Administrator(s). }\end{array}$ \\
\hline Design Authority & $\begin{array}{l}\text { S.G. Spencer } \\
\text { (LMHC-BMO) }\end{array}$ & $\begin{array}{l}\text { - } \text { CCB Chair and selects CCB members. } \\
\text { - } \quad \text { Represents owner(s) in approvals. } \\
\text { - } \quad \text { Approves test criterion and test results of changes before placing in operation. } \\
\text { - } \quad \text { Screens VCR Verification and Validation (V\&V) Plan and Maintenance Test Plan (MTP) for appropriateness for SCR/PR(s). } \\
\text { - } \quad \text { Assigns V\&V TCBD Document Revicwers, and oversees resolution of V\&V RCRs. }\end{array}$ \\
\hline $\begin{array}{l}\text { Software } \\
\text { Administrator }\end{array}$ & $\begin{array}{l}\text { S. G. Spencer } \\
\text { (LMHC-BMO) }\end{array}$ & $\begin{array}{l}\text { - Controls authorized users, priviliege levels, and passwords. } \\
\text { - } \quad \text { Averall responsibility for SCM. } \\
\text { - Assigns Lead Engineer/Design Agent(s). } \\
\text { - Assigns Software Custodian. }\end{array}$ \\
\hline Lead Engineer & $\begin{array}{l}\text { M.A. Favro } \\
\text { (LMSI) }\end{array}$ & $\begin{array}{l}\text { - } \\
\text { - } \\
\text { - } \\
\text { - } \quad \text { Evaluates and implements guidance/coordinates testing (including reviews/independence/witnesses), and verification and validation activities. } \\
\text { - } \quad \text { Maintains SCR/PR for impact on cost, schedule, and deliverables. } \\
\text { - Groups SCR/PR(s), V\&V forms, and Test Information (TD) forms for release into production environment. } \\
\text { - Maintains a library of all associated correspondence, personnel assignments, documentation, deliverables, reports, logs, } \\
\text { sofware, vendor information, etc., in their most up-to-date version. }\end{array}$ \\
\hline $\begin{array}{l}\text { Change Control } \\
\text { Board Chair }\end{array}$ & $\begin{array}{l}\text { S. G. Spencer } \\
\text { (LMHC-BMO) }\end{array}$ & $\begin{array}{l}\text { - Accepts/prioritizes work proposed by SCR/PR. } \\
\text { - Approves or disapproves completed testing results from SCR/PR implementation. }\end{array}$ \\
\hline $\begin{array}{l}\text { Software Developer } \\
\text { and Maintainer }\end{array}$ & $\begin{array}{l}\text { M.A. Favro } \\
\text { (LMSI) }\end{array}$ & $\begin{array}{l}\text { - } \quad \text { Provides development and maintenance. } \\
\text { - Fills out TI forms with input from Sottware Engineering staff, Lead Engineer, and Design Authority. } \\
\text { - Fills out V\&V Matrix with input from Software Engineering staff, Lead Engineer, and Design Authority. } \\
\text { - Notifies vendors of hardware or software related SCRPR(s). }\end{array}$ \\
\hline Software Custodian & $\begin{array}{l}\text { M.A. Favro } \\
\text { (LMSI) }\end{array}$ & $\begin{array}{l}\text { - Ensures backup and recovery of application and software. } \\
\text { - Ensures proper labeling and storage of backup media. } \\
\text { - Ensures correct software is installed for production use. } \\
\end{array}$ \\
\hline Software Engineer(s) & $\begin{array}{l}\text { M.A. Favro } \\
\text { (LMSI) }\end{array}$ & $\begin{array}{l}\text { - } \\
\text { - Enforms the work identified in SCR/PR and conducts tests. } \\
\text { - Documents test results and includes with change request, or indicates supporting document number if applicable. } \\
\text { - Ensure use of independent review, testing, and/or witnesses, as appropriate. }\end{array}$ \\
\hline $\begin{array}{l}\text { Any Organization } \\
\text { Involvod with TCBD } \\
\text { Development or Operation }\end{array}$ & $\begin{array}{l}\text { Any User } \\
\text { (LHMC-TCBD) }\end{array}$ & $\begin{array}{l}\text { Identifies and report problems on a SCR/PR form. } \\
\text { Submits changes on a SCR/PR form. }\end{array}$ \\
\hline
\end{tabular}




\subsection{POLICIES AND PROCEDURES}

Configuration management of TCBD will be in accordance with HNF-PRO-429, Software Practices - Development Management, with guidance from HNF-PRO-555, Software Practices System Configuration Management Plan; HNF-PRO-464, Software Practices - Software Control; and HNF-PRO-469, Software Practices - Change Request and Problem Report, particularly with regard to SCR/PR and document approvals.

\section{SOFTWARE CONFIGURATION MANAGEMENT ACTIVITIES}

\subsection{CONFIGURATION IDENTIFICATION}

\subsubsection{Application Software}

Associated design basis documentation that establishes the foundation for the configuration of the TCBD system description has been released in as-built format. The design basis can be found in the High-Level Software Requirements Specification for the TWRS Controlled Baseline Database System (LMHC 1998a).

Each production software release shall be a grouping of the code and executable software products, and any modifications to vendor software (e.g., configurations, etc.). The release is assigned a unique release number by the TCBD developer.

Software will be identified as follows: As a minimum, each version of the TCBD software released for use will have a version identification number. Version numbers for major changes will be identified with an increasing number (i.e., 1.00, 2.00, and 3.00). Version numbers for minor changes will be identified with a revision number followed by a leading zero, and followed by an increasing number (i.e., 1.01, 1.02, and 1.03). If the change is a debug, then follow the same rules for a minor change and add an alpha (i.e., 1.01a, 1.01b, and 1.01c).

A designator will also be used to designate the TBCD phase (Acceptance Test Procedure [ATP] for acceptance testing, Operational Test Procedure [OTP] for operational testing, or Operations for an operational system or integration). The software release number is of the form R.r as described in HNF-PRO-464. Refer to Section 8 of the sample form in the "Release Cover Sheet and Revision Record" (Appendix B).

\subsubsection{Software Products}

Each software product (e.g., the application software development packages, the $\mathrm{O} / \mathrm{S}$ software, the network communications software, etc.) is assigned a unique product name and release version number. This product name and version number will be used as identification as much as practical on the same form in Section 7 (Appendix B). 


\subsubsection{Automatic Data Processing Hardware}

The Automatic Data Processing (ADP) hardware for the TCBD system is identified by vendor brand name, model number, and by specifications that the equipment must meet. At the Hanford Site, specific equipment is identified by a procurement control number affixed by the Procurement Group upon receipt of the equipment onsite. Procurement for the ADP hardware for the TCBD is controlled by HNF procedures and is outside the scope of this document.

Location of computer hardware is controlled by the TWRS BMO (Master Planning Group). Configuration control is required by the TCBD SCMP in the following cases: 1) identification of the minimum equipment necessary for operation, and 2) evaluation of impact caused by interface hardware changes that are part of the design basis documentation set via an SCR/PR.

\subsubsection{Documentation}

Each TCBD document is assigned a unique title, identification number, and revision number in accordance with site HNF supporting documentation procedures. The title, number, and revision number is also listed on the "Release Cover Sheet and Revision Record" in Section 6 (Appendix B) at the time of release. This cover sheet is used to document each individual release. A set of release documents consists of SCR/PR(s), test records, and V\&V documentation. Each set of release documents is processed via ECN into the TCBD System Release and Change Record (LMHC 1998d).

The TCBD SCR/PR forms shall be kept in local project files in log form by the Lead Engineer. When a release of a revised TBCD system occurs, the Lead Engineer will either 1) establish a file with the information related to that release, or 2) produce an HNF document to formally document the release sheet and associated SCR/PRs.

If the change is significant, a computer security evaluation form may need to be completed (form A-6700-382). Refer to HNF-PRO-434, Software Practices - Maintenance for more information.

\subsubsection{Application Reports}

Control of application reports generated by the TCBD system is not provided under this SCMP, and is the responsibility of the software end user organizations.

\subsubsection{Removable Media Labels}

Removable TCBD baseline system media shall be labeled consistent with the information contained in the HNF-PRO-464, Software Practices - Software Control. Removable media includes, but is not limited to, CD-ROMs, 3.5 in. floppy disks, ZIP disks, tapes, etc. 
Removable media will have the following information recorded on its label:

- Media identifier (i.e., disc number " $\mathrm{X}$ " of total number in set " $\mathrm{Y}$ ")

- Software identification

- Software revision identification ("R.r", "R" = major and " $r "$ = minor software changes)

- Software or data name or description

- Responsible organization and software custodian's name

- Recording date and time.

\subsubsection{Directory Nomenclature}

Original or backup source and executable software placed on media containing multiple versions/revisions shall be segregated using the available directory/subdirectory structure.

A major directory shall be provided for the software product, labeled with the product mnemonic. Subdirectories (or folders) shall be provided for each major revision. Each minor revision shall be contained in a separate sub-subdirectory, uniquely identified with the appropriate revision number. The subdirectory name shall contain the major and minor revision number, separated by a period. For example:

E: $\backslash T C B D \backslash R 1 \backslash R 1.0 \quad$ Contains all source and executables for the initial product release.

$\mathrm{E}: \backslash T C B D \backslash R 1 \backslash R 1.1 \quad$ Contains the source and executables for the first minor release.

E:ITCBD\R4LR4.3 Contains the source and executables for the third minor release of the fourth major product release.

\subsection{CONFIGURATION CONTROL}

All TCBD system change control originates with SCR/PR forms that are filled out and submitted by TCBD end-users. Two other TCBD documents exist to be used in conjunction with this SCMP for maintenance purposes; the System Maintenance Test Plan for the TWRS Controlled Baseline Database System (LMHC 1998b) (MTP), and the System Maintenance Verification and Validation Plan for the TWRS Controlled Baseline Database System (LMHC 1998c). A relationship chart for these three documents is shown in Appendix C.

The process flow diagram for implementing potential changes to the baseline TCBD system, including organizational responsibilities, is provided in Figure 1. See Appendix A for an example of the SCR/PR form. E-mail approvals for processing SCR/PRs may be substituted for handwritten approvals. When e-mail approvals are used, a copy of the e-mail approval must be attached to the SCR/PR. Telephone approvals for processing SCR/PRs may be used, but must be documented on the SCR/PR form or with an e-mail approval.

Revisions to the TCBD system documentation are processed in accordance with HNF-PRO-244, Engineering Data Transmittal Requirements and HNF-PRO-440, Engineering 
Document Change Control Requirements. These procedures are also used to process the transmittal of the "Release Cover Sheet and Revision Record" (Appendix B) to document a change in baseline per the SCR/PRs implemented. New versions and changes to the TCBD system software will be saved on appropriate media for release to the Software Custodian (per Section 2.2) for future retrieval.

\subsection{CONFIGURATION STATUS ACCOUNTING}

The configuration status of all controlled items is shown on the "Release Cover Sheet and Revision Record" (Appendix B). In addition, the status of all SCR/PRs and associated releases will be maintained and available in the TCBD SCR/PR logbook, available from the Lead Engineer.

\subsection{AUDITS AND REVIEWS}

The TCBD and associated documentation, including software change control, will be available for audit during established LHMC business hours. The TCBD Software Administrator should periodically audit the project file and change control documentation to ensure compliance. Other surveillance and audits are the responsibility of outside organizations and are outside the scope of this SCMP.

The Appendix B sheet is used as a cover sheet to document an individual release. A set of release documents consists of SCR/PR(s), test records, and V\&V documentation. Each set of release documents is processed via ECN into the TCBD System Release and Change Record (LMHC 1998d).

All changes and tests shall be reviewed and verified at an appropriate level. The System Maintenance Verification and Validation Plan for the TWRS Controlled Baseline Database System (LMHC 1998c) governs this process. Refer to Appendix C.

Should system changes require major modifications or enhancements, the Design Authority, Lead Engineer, and Software Developer and Maintainer will determine if a formal plan will be prepared. The formal plan will identify appropriate technical, V\&V, and Quality Assurance reviews that are consistent with HNF procedures and commensurate with the complexity of the change.

\subsection{ACCESS CONTROL}

Access control for operation of the TCBD software is provided by the application. It provides for an authorized user list and associated privilege levels. Authorized users are required to provide a user name and password. Authorized users and passwords for access will be assigned and controlled by the Software Administrator. The Software Administrator will authorize access only after appropriate training is provided. The TCBD software is protected to restrict those with access from altering the database functions inadvertently. 


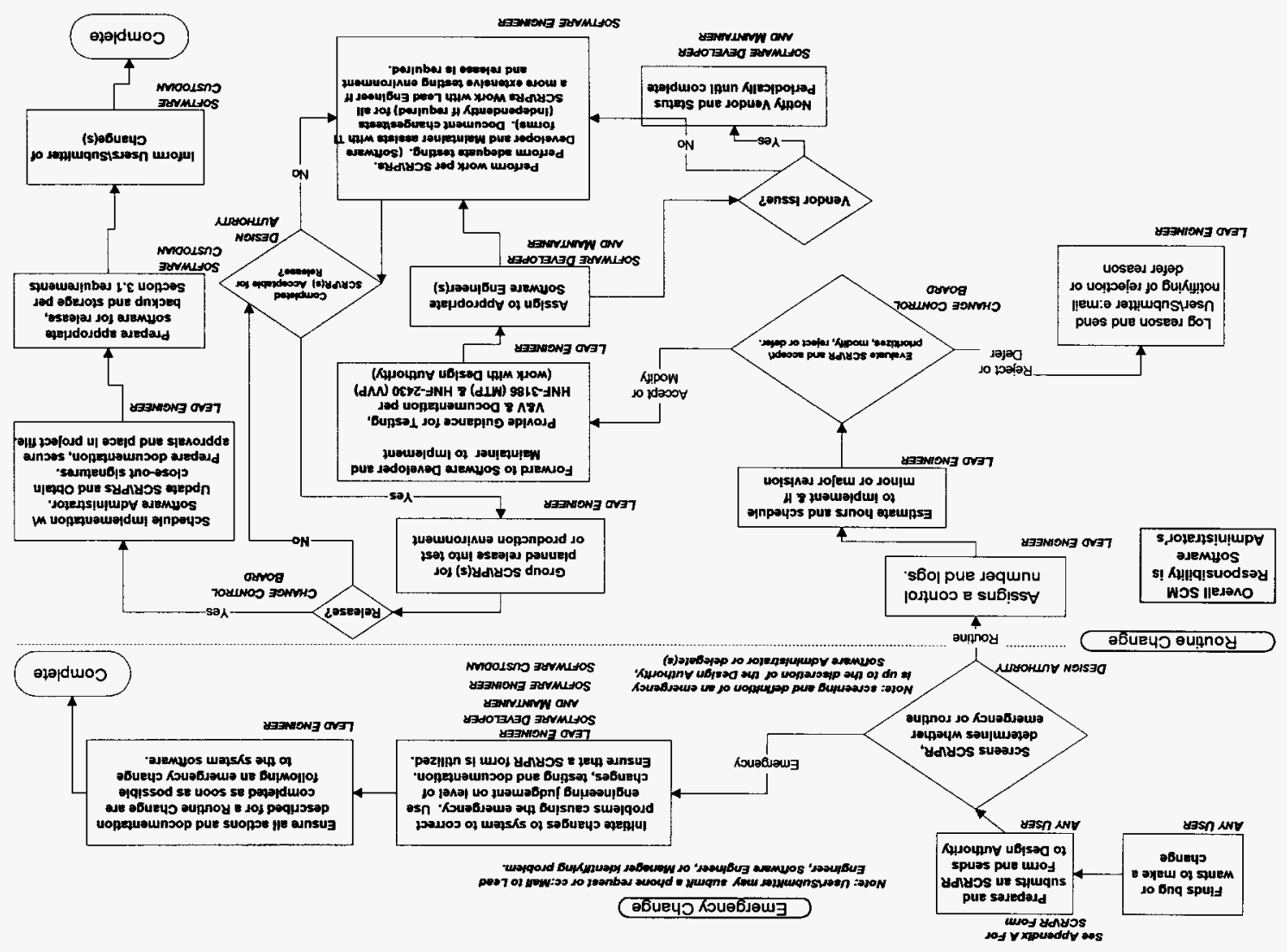

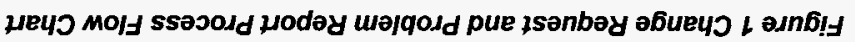

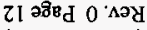

(dWOS (IROL) $6 Z \triangleright Z-A N H$ 


\subsection{BACKUP AND RECOVERY}

Backup of the source code and executable files that constitute each product release is performed by the Software Custodian onto the fileserver backup partition selected and documented by the Software Custodian--for example "ILMHC002\PROJECTSITBCDISCMP (see Section 3.1.7) at the time of release. The Software Custodian is responsible for verifying that the backup is in place and the appropriate files exist.

Recovery shall be accomplished by rewriting the appropriate files from the master media onto the production fileserver or its replacement. This shall be accomplished by the Software Custodian or Lead Engineer/Software Engineer as needed. Should the master media be simultaneously corrupted, recovery shall be from the backup fileserver partition.

\section{TOOLS, TECHNIQUES AND METHODOLOGIES}

\subsection{ADMINISTRATIVE TOOLS}

TCBD administration tools for implementation of this SCMP include the Responsibilities Matrix (Table 1), Change Request and Problem Report Process Flow Chart (Figure 1), SCR/PR form (Appendix A) and log, Release Cover Sheet and Revision Record (Appendix B), and TCBD System Maintenance Approach (Appendix C).

Software and hardware tools and training are outside the scope of this SCMP, but it is assumed that adequately trained personnel will invoke approved and appropriate system changes.

\subsection{TEST ENVIRONMENT}

All TCBD hardware and software modifications and enhancements will be completed and certified in a test environment where possible. The System Maintenance Test Plan for the TWRS Controlled Baseline Database System (LMHC 1998b) governs this process. Refer to Appendix C.

Changes will be implemented into the production environment only after the Design Authority has reviewed and approved the test results and the CCB has approved the implementation for production release. Modifications and enhancements will be grouped logically into production releases.

\section{SUPPLIER CONTROL}

The Software Developer will ensure that new releases and installation of the vendor application and software product are tested prior to its being placed in production. Changes in 
vendor application and/or software product will be processed as a change request or problem report with the same approval requirements as a locally generated change.

The Lead Engineer will maintain a project file, binder, or index of all vendor-provided materials, manuals, project documentation, correspondence, and project documents. This project file, binder or index will be maintained for use by all TCBD personnel, as required, for the life of the TCBD.

\section{RECORDS COLLECTION AND RETENTION}

The TCBD software developer will process software development and maintenance records in accordance with HNF-PRO-564, Software Practices - Records Retention and Disposal. Any items indicating "Forward to Records Management..." will instead be sent to the Lead Engineer. These records, at a minimum, include the SCR/PR logbook and SCR/PR form entries, and will be kept by the Lead Engineer in local project files.

\section{REFERENCES}

HNF-PRO-244, Engineering Data Transmittal Requirements, Fluor Daniel Hanford, Richland, Washington.

HNF-PRO-429, Software Practices - Development Management, Fluor Daniel Hanford, Richland, Washington.

HNF-PRO-434, Software Practices - Maintenance, Fluor Daniel Hanford, Richland, Washington.

HNF-PRO-440, Engineering Document Change Control Requirements, Fluor Daniel Hanford, Richland, Washington.

HNF-PRO-464, Software Practices - Software Control, Fluor Daniel Hanford, Richland, Washington.

HNF-PRO-469, Software Practices - Change Request and Problem Report, Fluor Daniel Hanford, Richland, Washington.

HNF-PRO-555, Software Practices - System Configuration Management Plan, Fluor Daniel Hanford, Richland, Washington.

HNF-PRO-564, Records Retention and Disposal, Fluor Daniel Hanford, Richland, Washington.

LMHC, 1997, Performance Measurement Control System Project Management Plan, HNF-SD-TWR-PMP-001, Rev. 0, Lockheed Martin Hanford Company, Richland, Washington. 
LMHC, 1998a, High-Level Software Requirements Specification for the TWRS Controlled Baseline Database System, HNF-3185, Rev. 0, Lockheed Martin Hanford Company, Richland, Washington.

LMHC, 1998b, System Maintenance Test Plan for the TWRS Controlled Baseline Database System, HNF-3186, Rev. 0, Lockheed Martin Hanford Company, Richland, Washington.

LMHC, 1998c, System Maintenance Verification and Validation Plan for the TWRS Controlled Baseline Database System, HNF-2430, Rev. 0, Lockheed Martin Hanford Company, Richland, Washington.

LMHC, 1998d, TCBD System Release and Change Record, HNF-3357, Rev. 0, Lockheed Martin Hanford Company, Richland, Washington 


\section{APPENDIX A: TCBD SOFTWARE CHANGE REQUEST AND PROBLEM REPORT FORM}

Any user may fill out a "Software Change Request" and Problem Report form describing a change or problem (see form below). The form should be sent to the appropriate individual at MSIN R1-19. This individual will log this form and track resolution.

\section{SOFTWHRE CHANGE REQUEST AND PROBLEM REPORT [SER/PR] FORM}

NOTE: User Fills In Parts 1-8 (NON-GRAY)

1. SCR: [ ] New Development [ ] Problem [ ] Enhancement [ ] Y 2K

2. Requested Completion Date:

3. Submitted By:

4. Software Program Name:

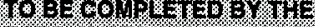

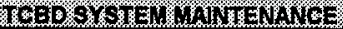

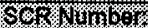

8110. 00 g6:

Ghatgedood

Cuition Wowhev.

5. Submitter's Priority [ ] (1= Critical $2=$ Important $3=$ Low Priority)

6. Task/Change/Problem Title (One Sentence Description):

7. Detailed Description/Justification (Attach Additional Sheet If Necessary):

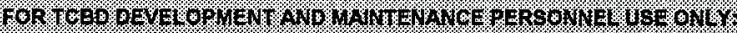

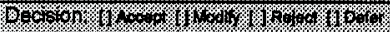

2.

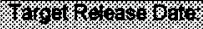

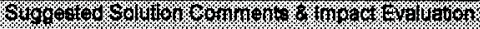

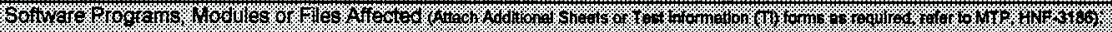

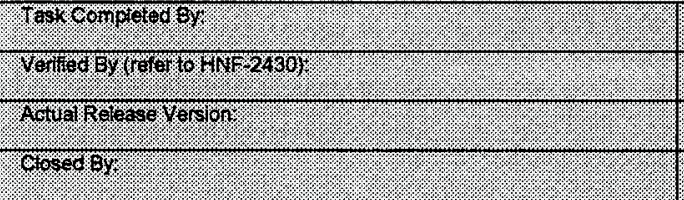

\subsection{9.}

80to

Vortex

Yax 


\section{APPENDIX B: TCBD RELEASE COVER SHEET AND REVISION RECORD FORM}

\section{RELENSE COUER SHIFI AND REVISION RECORD}

1. Software ID (Name):

2. Release Type: [ ] Initial Release [ ] Change

\section{Revision:}

[ ] Quality Affecting

3. Listing of SCR/PR(s) Attached and Abstract (attach all SCR/PR(s), V\&V documents. TI Forms, and all relevant documentation)

4. Software Files (or attach directory listing)

5. Software files record storage media and location

\begin{tabular}{|c|c|c|c|}
\hline 6. Documentation & Title & Number & Revision \\
\hline Requirements & & & \\
\hline Design & & & \\
\hline Design Verif. & & & \\
\hline Validation & & & \\
\hline User & & & \\
\hline Config. Cntt. & & & \\
\hline 7. Environment & Description & & Revision \\
\hline Hardware & & & \\
\hline Oper. Software(s) & & & \\
\hline Language(s) & & & \\
\hline Comm. Networks & & & \\
\hline $\begin{array}{l}\text { 8. Released for: } \\
\text { [ ] ATP [ ]OTP }\end{array}$ & [ ] Operations & & \\
\hline 9. Approvals & & & \\
\hline Design Authority: & & & Date: \\
\hline Lead Engineer: & & & Date: \\
\hline Software Administrator & & & Date: \\
\hline
\end{tabular}




\section{APPENDIX C: TCBD SCMP, V\&V PLAN, AND MTP RELATIONSHIP CHART}

\section{TEBD SYSTEM MAINIEMANCE APPROACH}

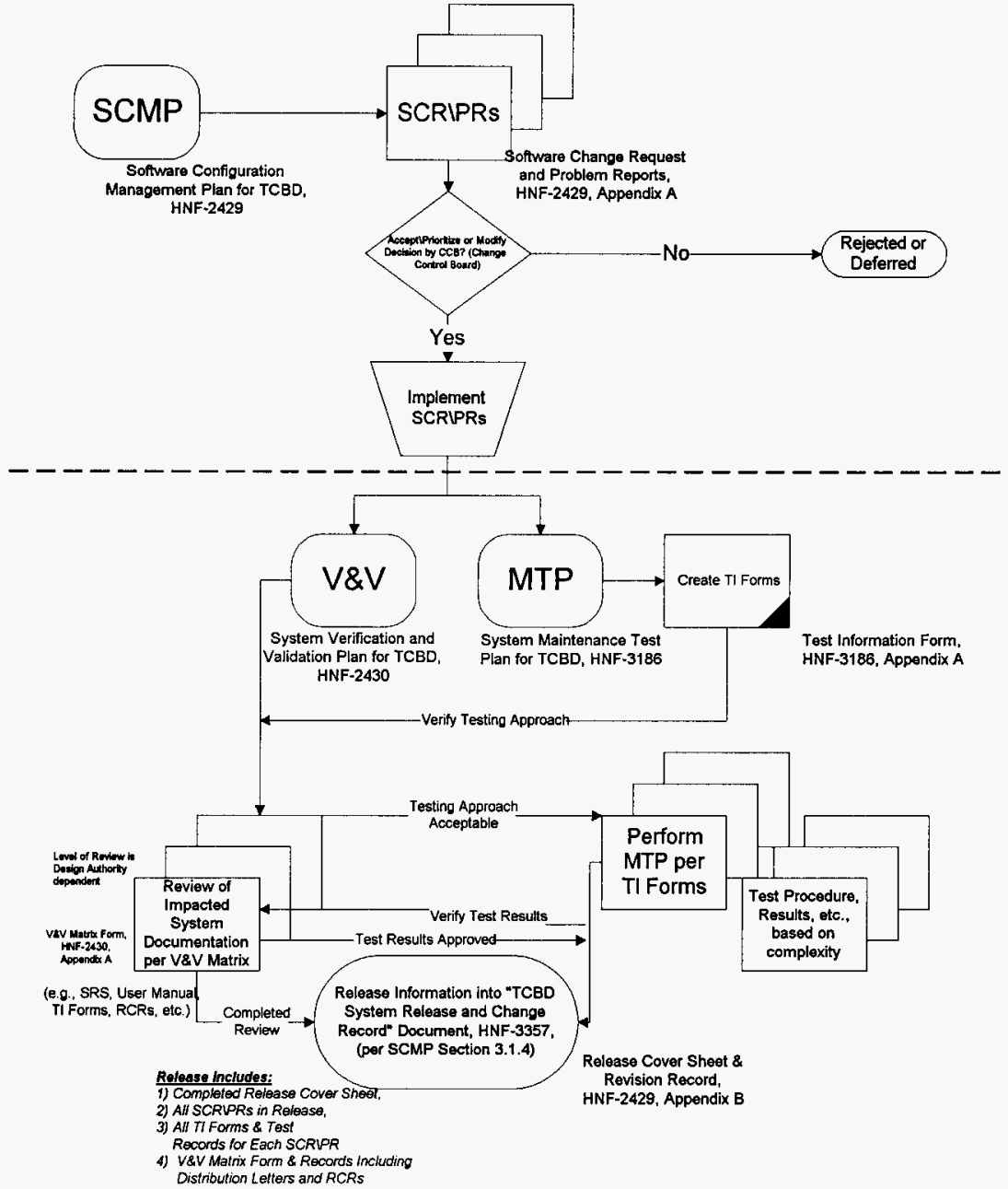

